
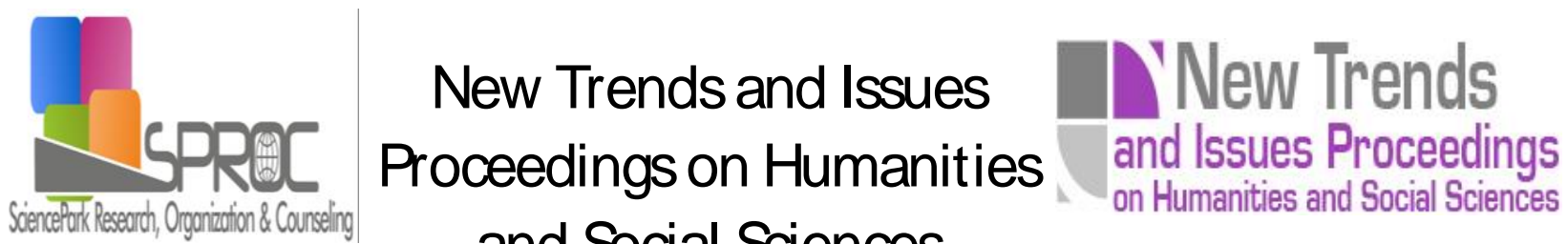

\title{
The effect of leadership styles on professional learning community
}

Wallapha Ariratana *

Saowanee Sirisookslip

Tang Keow Ngang

Suggested Citation:

c c c lacc fft l fffft lafft afft ac !

Abstract 
lacc fft I fffft lafft afft ac !

1. Introduction

2. Statement of problem 
lacc fft I Iffft lafft afft ac !

3. Operational definition

4. Significance of the study 
lacc fft I Iffft lafft afft ac !

\section{Conceptual framework}

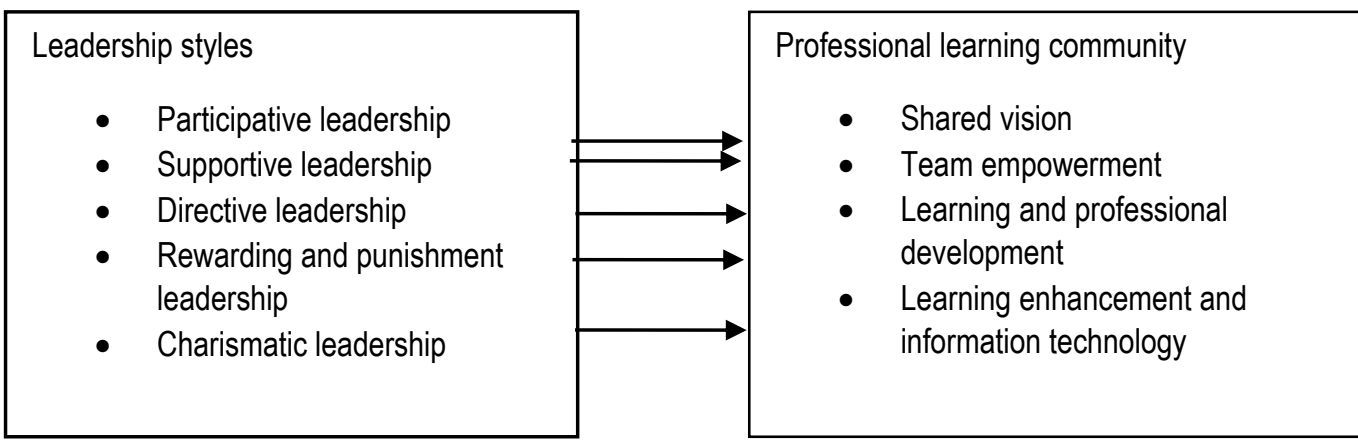

Fig. 1. Conceptual framework.

\section{Research objectives}

\section{Research methodology}


lacc fft I fffft lafft afft ac !

8. Findings 
lacc fft I Ifffft lafft ac ! 
Table 3. Designation strength of association based on size of correlation coefficients.

Table 4. Correlation coefficient between leadership styles and professional learning community. 
lacc fft I Iffft lafft afftac !

Table 5. Multiple regression of leadership styles and professional learning community. $\beta$

$\hat{Y}$

$\hat{Y}$

9. Discussion 
lacc fft I Iffft lafft afft ac !

Acknowledgements

References

fft l afft afftac $r$

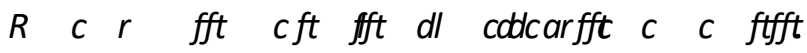

H $\quad 9$

c c ftft fftrfft c cl c r

aft I fft $c \quad c \quad c \quad r$

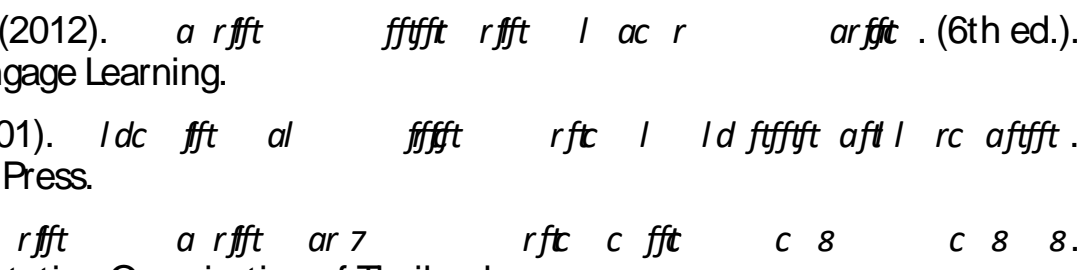




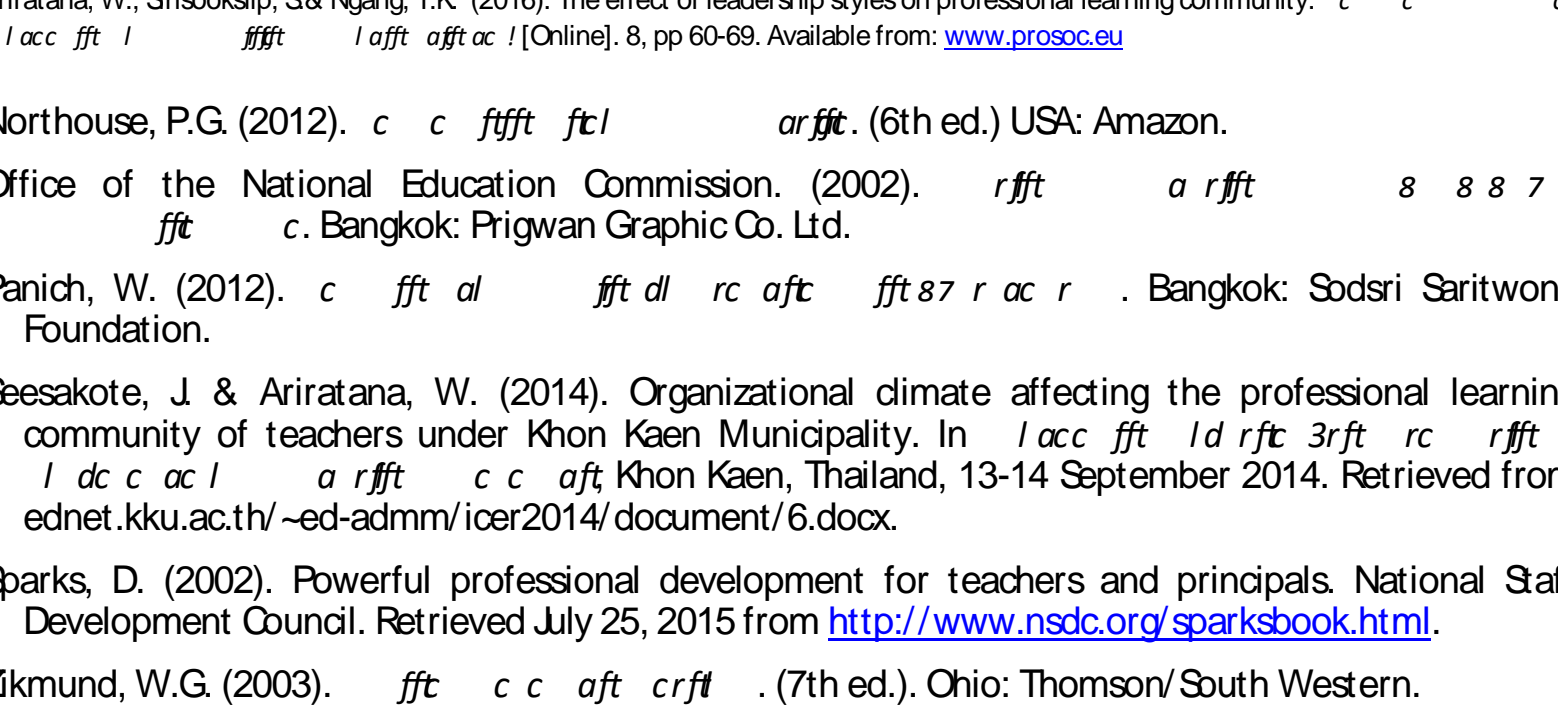

